\title{
A (in)visibilidade dos Direitos Humanos nos cursos de licenciatura em Educação Física de universidades federais brasileiras
}

https://doi.org/10.11606/issn.1981-4690.v35i3p99-112

\author{
Lana Lisiêr de Lima Palmeira* \\ Carla Priscilla Barbosa Santos Cordeiro* \\ Antonio Gottschlisch do Prado** \\ Edna Cristina do Prado*
}

*Universidade Federal de Alagoas, Maceió, AL, Brasil.

${ }^{* *}$ Escola Superior de Educação Física de Jundiaí, Jundiaí, SP, Brasil.

\section{Resumo}

O presente artigo tem com objeto de investigação a formação de licenciados em Educação Física e visa compreender seos elementos que dão corpoà Educaçãoem Direitos Humanos estão inseridos na referida formaçãoe,emestando,seessapresençasedádeformasatisfatórianosentidodenãoapenasformarpessoas aptastãosomenteasaberesecompetênciastécnicas, massebuscaforjá-lasemsuaintegralidade,tornandoas sujeitos de direitos na acepção mais ampla do vocábulo. A partir de uma abordagem qualitativaà luz da Análise deConteúdo, discuteconceitosfundantes daEducaçãoem Direitos Humanosedopreconizadonas Diretrizes Curriculares Nacionais que regulam os cursos de Educação Física para empreender a análise dos projetos político-pedagógicos edoscurrículos dos cursos delicenciatura em Educação Física, mais antigos, ofertados nas universidades federais brasileiras. Os resultados revelam a subalternização dos elementos humanísticos em comparação aos conteúdos técnicos e a conclusão do estudo reforça a necessidade de mais pesquisas acerca da temática em tela e a convicção de que, de alguma forma, a reflexão apresentada pode contribuir para as searas que retroalimentam o humanismo na ambivalência universitária.

Palavras-Chave: Educação em direitos humanos; Universidades federais; Educação Física.

\section{Introdução}

O móvel originário deste estudo foi formação dos autores, visto que, sendo dois deles da área específica da Educação Física, somados a mais duas doutoras em Educação, assumem uma linha de trabalhos em prol dos postulados da Educação em Direitos Humanos, já trilhando, de certa forma, caminhos no sentido de observar a preparação dos futuros profissionais, tomando por base a formação propagada na ambiência universitária.

Assim, ao se inquietarem com algumas percepções cotidianas e resolvendo sair do campo apenas das curiosidades ingênuas, buscaram adentrar, de forma epistemológica, em mais uma pesquisa que viesse a responder tais inquietudes.

Seguindo esse raciocínio, este trabalho tem como objeto de investigação a formação dos futuros profissionais de Educação Física no Brasil, a fim de entender se os elementos que dão corpo à
Educação em Direitos Humanos estão inseridos na referida formação e, em estando, se essa presença se dá de forma satisfatória no sentido não só de formar pessoas para o exercício de uma profissão, aptas a desenvolverem tão somente saberes e competências técnicas da sua atuação específica, mas sim se busca trabalhar verdadeiramente a pessoa na sua integralidade, isto é, em uma visão mais ampla que permita desenvolver, dentre outros aspectos, senso crítico, capacidade reflexiva e outros fatores que geram o empoderamento individual e coletivo, capaz de tornar essas pessoas sujeitos de direitos na acepção mais ampla do vocábulo.

Em outras palavras, significa dizer que, diante do cenário atual, em que parece preponderar a preparação para empregabilidade, seguindo os ditames mercadológicos do capital, nota-se por diversas vezes a existência de currículos organizados 
em núcleos rígidos voltados para o ensinamento de matérias direcionadas meramente à formação técnico-profissional, deixando em segundo plano a formação humanística, razão pela qual se entendeu necessário o presente estudo, cuja abordagem iniciou com a discussão dos conceitos mais elementares em torno da Educação em
Direitos Humanos, dando abertura a um caminho que conduziu ao que está preconizado nas Diretrizes Curriculares Nacionais que regulam os cursos de Educação Física no Brasil, chegando ao ápice do estudo, a saber: a análise dos projetos político-pedagógicos e currículos dos referidos cursos no país.

\section{Método}

Com as delimitaçóes acima apresentadas e assumindo uma natureza qualitativa, optou-se por utilizar a Análise de Conteúdo ${ }^{1}$ como técnica de análise que objetiva a inferência de conhecimentos pertinentes às condições de produção e recepção das mensagens enunciadas.
Assim sendo, teve início o acesso ao sistema eletrônico de acompanhamento dos processos que regulam a educação superior no Brasil (e-MEC), no qual estão catalogadas 2131 instituiçóes de ensino com o curso de Educação Física², conforme TABELA 1.

TABELA 1 - Número total de instituições de ensino que ofertam o curso de Educação Física, divididas por categoria administrativa.

\begin{tabular}{lc}
\hline Categoria Administrativa & Total \\
\hline Pública Municipal & 39 \\
Pública Federal & 128 \\
Pública Estadual & 167 \\
Privada sem fins lucrativos & 745 \\
Privada com fins lucrativos & 1036 \\
Especial & 16 \\
& Total Geral \\
\hline
\end{tabular}

Todavia, partindo para uma análise pormenorizada, verificou-se que dessas IES, existem, de fato, 1925 em atividade, sendo que, ao realizar uma subdivisão por categoria administrativa, tem-se que 36 delas são instituições públicas municipais; 124 são públicas federais; 153 são públicas estaduais; 691 são privadas sem fins lucrativos; 906 são privadas com fins lucrativos e 15 se encaixam na categoria de instituições especiais de ensino, conforme se denota na FIGURA 1.

Detalhando ainda mais tais achados e focando a atenção apenas nas 124 instituiçóes Públicas Federais em atividade, passou-se a analisar cada uma delas com o intuito de verificar se a oferta do curso acontece como bacharelado ou licenciatura (TABELA 2). 
FIGURA 1 - Instituições de Educação Física em atividade, divididas por categoria administrativa.

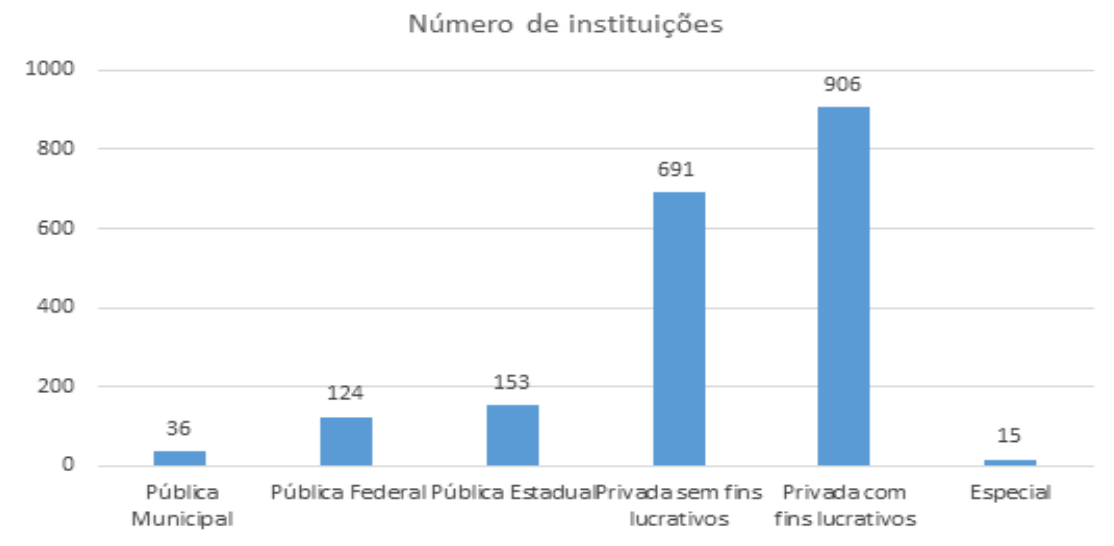

Fonte: Ministério da Educação. Sistema e-MEC, 2021.

TABELA 2 - Divisão das IFES brasileiras em atividade, no tocante ao grau conferido ao curso de Educação Física ofertado.

\begin{tabular}{|c|c|}
\hline Grau da instituiçáo & Total \\
\hline Bacharelado & 42 \\
\hline Licenciatura & 82 \\
\hline Total Geral & 124 \\
\hline
\end{tabular}

Fonte: Ministério da Educação. Sistema e-MEC, 2021
Ressalta-se que, diante da impossibilidade de analisar todas as instituiçóes de ensino que ofertam o curso de Educação Física no Brasil, adotouse, como critérios de seleção, apenas os projetos político-pedagógicos e matrizes curriculares das universidades federais com cursos de licenciatura. Tal critério de escolha se deu em face à estrutura organizacional que permeia as universidades em seus mais amplos aspectos, o que poderia trazer respostas mais fidedignas ao objeto da investigação. No que concerne à escolha das licenciaturas, tal fato se deu não apenas por serem as mesmas com o percentual mais representativo das ofertas existentes, com número quase $100 \%$ maior que os bacharelados, mas também por ser a licenciatura que prepara o estudante para a docência e, assim sendo, merecendo ter uma melhor fundamentação nos pilares da Educação em Direitos Humanos.

Todavia, mesmo com tais critérios, constatou- se ser o universo de estudo ainda muito amplo, necessitando de um novo recorte a fim de se ter uma análise mais completa acerca do objeto de investigação. Assim, lançou-se mão de mais dois critérios de seleção: trabalhar tão somente os cursos de licenciatura presenciais em Educação Física e apenas com os cursos mais antigos de cada região brasileira. Eis que dos 82 cursos de licenciatura, 72 se dão na referida modalidade e as cinco universidades, evidenciadas no quadro abaixo, são as que possuem os cursos mais antigos em suas regióes (QUADRO 1).

Com o corpus delimitado, passou-se à escolha das categorias analíticas, quais sejam: presença da disciplina Direitos Humanos ou Educação em Direitos Humanos nos projetos políticos pedagógicos e currículos, bem como a proporção das disciplinas de formação humanística em relação às disciplinas tecnicistas nos referidos projetos pedagógicos e currículos. 
QUADRO 1 - Cursos mais antigos de Licenciatura em Educação Física, presenciais, nas Universidades Públicas Federais, por regiões brasileiras.

Fonte: Ministério da Educação. Sistema e-MEC, 2021.

\begin{tabular}{lllll}
\hline Regiáo & \multicolumn{1}{c}{ Instituiçáo (IES) } & Estado & Sigla & Data Ato de Criaçáo \\
\hline Sudeste & Universidade Federal do Espírito Santo & ES & UFES & $24 / 09 / 1936$ \\
Sul & Universidade Federal do Rio Grande do Sul & RS & UFRGS & $27 / 05 / 1941$ \\
Norte & Universidade Federal do Amazonas & AM & UFAM & $24 / 02 / 1969$ \\
Nordeste & Universidade Federal de Pernambuco & PE & UFPE & $01 / 09 / 1972$ \\
Centro-oeste & Universidade Federal de Mato Grosso & MT & UFMT & $10 / 12 / 1970$ \\
\hline
\end{tabular}

\section{Elementos centrais em torno da educaçáo em direitos humanos no Brasil}

Inicialmente, deve-se ressaltar que a Declaração Universal dos Direitos Humanos de 1948 foi um marco significativo na luta pelas liberdades humanas, impulsionando uma série de preocupaçóes em torno da necessidade de se consagrar princípios que fossem respeitados por todas as naçóes.

Adentrando no panorama brasileiro, não se pode deixar de tecer algumas consideraçóes sobre a política nacional de direitos humanos no Brasil, visto que ela repercute na concepção de direitos humanos difundida por vários segmentos que tratam da matéria, desde o período marcado pela oposição ao autoritarismo vigente no país durante a década de 70 .

Recebendo forte impulso da II Conferência Mundial realizada em Viena, a qual propugnava que os Estados membros das Nações Unidas concebessem programas nacionais de direitos humanos, tem-se que praticamente só após quase 50 anos da promulgação da Declaraçáo Universal de Direitos Humanos de 1948, tais direitos foram contemplados como política oficial de governo, dissonando, assim, da conjuntura sóciopolítica entáo vigente.

Imperioso realçar que o Brasil foi um dos países pioneiros na promoção dessa política, tendo, em 1996, a elaboraçáo do seu primeiro Programa Nacional de Direitos Humanos (PNDH), tendo como característica preponderante a ênfase na garantia dos direitos civis, assegurando maior proteção à integridade física, à cidadania e, consequentemente, à liberdade.

Em 2001, foi iniciada uma série de trabalhos em prol da formatação do PNDH II, que teve nessa versão a inclusão dos direitos sociais, econômicos e culturais de acordo com os princípios da indivisibilidade e da interdependência dos direitos humanos previstos na Declaração e no Programa de Ação da Conferência de Viena.

Já o PNDH III, elaborado em 2009 e que se encontra em vigor atualmente, diferentemente dos programas anteriores, apresentou na sua elaboração o envolvimento de vários atores sociais, em face à realização da $11^{\text {a }}$ Conferência Nacional dos Direitos Humanos.

No que pertine à educação, objeto mais específico deste estudo, o PNDH III estabelece cinco diretrizes basilares, a saber: efetivação das diretrizes da política nacional em Direitos Humanos; fortalecimento dos princípios da democracia e dos Direitos Humanos em todos os níveis da educaçáo; reconhecimento da educação não formal na defesa dos Direitos Humanos; promoção da Educação em Direitos Humanos no serviço público, garantia da comunicação democrática e do acesso à informaçáo acerca dos Direitos Humanos ${ }^{3}$.

Observa-se, dessa forma, que a educação é trabalhada no PNDH III não só como um direito humano, mas também como uma garantia fundante à consecução de outros direitos, sendo visualizada como um conjunto de procedimentos de educação formal e não formal, voltado à edificação de uma cultura de respeito à dignidade humana.

No que diz respeito ao Plano Nacional de Educação, Lei no ${ }^{\circ} 13.005 / 2014$, observa-se que seu elo de ações pelo viés da Educação em Direitos Humanos está positivado logo no artigo $2^{\circ}$ : 
São diretrizes do PNE: [...] II - universalização do atendimento escolar; III - superação das desigualdades educacionais, com ênfase na promoção da cidadania e na erradicação de todas as formas de discriminação; [...] V - formação para o trabalho e para a cidadania, com ênfase nos valores morais e éticos em que se fundamenta a sociedade; [...] VII - promoção humanística, científica, cultural e tecnológica do país; [...] X - promoção dos princípios do respeito aos direitos humanos, à diversidade e à sustentabilidade socioambiental ${ }^{4}$.

Seguindo essa linha de análise e caminhando um pouco mais nas trilhas do PNE, denota-se no $₫ 1^{\circ}$ do artigo $8^{\circ}$, que:

$\$ 1^{\circ}$ Os entes federados estabelecerão nos respectivos planos de educação estratégias que: [...] II - considerem as necessidades específicas das populaçóes do campo e das comunidades indígenas e quilombolas, asseguradas a equidade educacional e a diversidade cultural; III garantam o atendimento das necessidades específicas na educação especial, assegurado o sistema educacional inclusivo em todos os níveis, etapas e modalidades $[\ldots]^{4}$. (Grifos nossos).

Vê-se que no artigo acima há a remissão clara a pelo menos dois aspectos de ampla discussão no contexto da Educação em Direitos Humanos, a saber: a diversidade sociocultural e a educação inclusiva, o que já mostra a presença, pelo menos no prisma normativo, desses elementos de importância ímpar ao cenário educacional do país.

Como já fora exteriorizado anteriormente, a Declaração Universal representou um verdadeiro divisor de águas dos Direitos Humanos, surgindo em 1948 e já fazendo menção, no seu artigo 26, ao direito à educação, destacando que:

A instrução será orientada no sentido do pleno desenvolvimento da personalidade humana e do fortalecimento do respeito pelos direitos do ser humano e pelas liberdades fundamentais. A instrução promoverá a compreensão, a tolerância e a amizade entre todas as naçôes e grupos raciais ou religiosos e coadjuvará as atividades das Naçôes Unidas em prol da manutenção da paz 5 .

Também a Lei de Diretrizes e Bases da Educação Brasileira de 1996, em seu artigo $1^{\circ}$, já começa a evidenciar indicadores relacionados à Educação em
Direitos Humanos, ao preceituar que

[...] a educação abrange os processos formativos que se desenvolvem na vida familiar, na convivência humana, no trabalho, nas instituiçôes de ensino e pesquisa, nos movimentos sociais e organizaçôes da sociedade civil e nas manifestaçōes culturais ${ }^{6}$.

Chegando ao Plano Nacional de Educação em Direitos Humanos (PNEDH), observa-se que o referido documento estabelece diversos programas intencionando a inserção de uma perspectiva educacional voltada à formação da cidadania ativa, ou seja, há um ideal de se atingir a concretização de uma prática pedagógica norteada pelos direitos humanos, na sua essência mais elementar, que corrobora, antes de tudo, a dignidade da pessoa humana como elemento basilar de qualquer atividade social.

No tocante à educação superior, de acordo com o postulado pelo PNEDH, sua contribuição à área da educação em direitos humanos deve pautar-se nos seguintes princípios:

a) a universidade, como criadora e disseminadora de conhecimento, é instituiçấo social [...] comprometida com a democracia e a cidadania;

b) os preceitos da igualdade, da liberdade e da justiça devem guiar as açôes universitárias, de modo a garantir a democratizaçáo da informação, o acesso por parte de grupos sociais vulneráveis ou excluídos e o compromisso cívico-ético com a implementação de políticas públicas voltadas para as necessidades básicas desses segmentos;

c) o princípio básico norteador da educação em direitos humanos como prática permanente, contínua e global, deve estar voltado para a transformaçāo da sociedade [...]

d) a educação em direitos humanos deve se constituir em princípio ético-político orientador da formulação e crítica da prática das instituiçôes de ensino superior;

e) [...] formaçáo de uma cultura baseada na universalidade, indivisibilidade e interdependência dos direitos humanos, como tema transversal e transdisciplinar, de modo a inspirar a elaboração de programas específicos e metodologias adequadas nos cursos de graduação e pós-graduação, entre outros;

\section{$[\ldots]$}

g) o compromisso com a construçáo de uma cultura de respeito aos direitos humanos na relação com os movimentos e entidades sociais, além de grupos em situação de exclusão ou discriminação;

h) a participação das IES na formação de agentes sociais de educação em direitos humanos e na avaliaçẫo do processo de implementação do PNEDH (p. 38-39)3. 
Depreende-se que os ideais acima propostos visam disseminar um processo educacional diferenciado, que se afaste do "tecnicismo" e leve o estudante a ser agente de interação e transformação social, já que, conforme se observa, vigora ainda um modelo estrutural voltado ao formalismo, distanciado de um prisma humanitário que se entende necessário aos paradigmas ora defendidos.

Nesse prisma, PNEDH elenca, ainda, 21 açóes programáticas que convergem não apenas para a necessidade de se ter uma educaçáo calcada na interdisciplinaridade, na transdisciplinaridade e na pluridisciplinaridade, mas também na indissociabilidade existente na trilogia universitária, materializada por meio do ensino, da pesquisa e da extensão, a fim de que, guiado pelo olhar da educação em Direitos Humanos, haja a reformulaçáo do conhecimento e, consequentemente, a concretização dos valores do empoderamento individual e coletivo.

Só por meio de uma educação emancipatória, que observe os parâmetros já trazidos à cena, poder-se-á pensar na superação do tecnicismo dominante que marca a educação na atualidade. Afinal, como pontua SANTOS $^{7}$ ao se referir à Universidade pós-moderna:

O conhecimento-emancipaçáo tem de converter-se num senso comum emancipatório: impondo-se ao preconceito conservador e ao conhecimento prodigioso e impenetrável, tem de ser um conhecimento prudente para uma vida decente (p. 107)

Assim, de acordo com a sequência de ideias apresentada, buscar-se-á trabalhar, na seção seguinte, as Diretrizes Curriculares Nacionais que norteiam os cursos de Licenciatura em Educação Física no país, buscando estabelecer identificaçôes entre elas e o que fora vislumbrado nas linhas anteriores no tocante às normativas da Educação em Direitos Humanos.

\section{Análise das diretrizes curriculares nacionais}

As Diretrizes Curriculares Nacionais (DCN) do curso Educação Física estão previstas na Resolução $\mathrm{n}^{\mathrm{o}} 6$ de 18 de dezembro de 2018 e trazem aspectos relacionados à organização, princípios, finalidades e à dinâmica formativa que deve ser observada pelas instituiçóes de ensino por todo o país. Nelas, a Educação Física é trazida como uma área de conhecimento em que os indivíduos são capazes, de um lado, de estudar e conhecer a motricidade ou movimento humano, bem como a cultura que envolve o movimento corporal a partir dos exercícios físicos, que abrangem, por exemplo, todos os tipos de esporte e a dança. Além da compreensáo deste conhecimento, o profissional que atua com a Educação Física deve ser capaz de aplicá-los, levando em consideração as necessidades sociais relacionadas à saúde humana, à formação dos indivíduos, ao aspecto cultural que envolve a prática de atividades físicas, ao rendimento do esporte e ao lazer (artigo $\left.3^{\circ}\right)^{8}$.

Dentre os valores que norteiam os objetivos do curso, as DCN preconizam a capacidade de compreensão e aplicação dos conhecimentos relacionados à Educação Física com o desenvolvimento da pessoa (ora individualizada) e da sociedade, uma vez que o direito à saúde e ao desenvolvimento social emergem como uma das missóes basilares dos profissionais dessa área.

Embora o estudante tenha que optar entre a formação em licenciatura ou bacharelado, as $\mathrm{DCN}^{8}$ preveem um ingresso único à formação na graduação, o que deve ser feito em duas etapas, de acordo com seu artigo $5^{\circ}$ :

I - Etapa Comum - Núcleo de estudos da formação geral, identificador da área de Educaçâo Física, a ser desenvolvido em 1.600 (mil e seiscentas) horas referenciais, comum a ambas as formaçōes.

II - Etapa Específica - Formação específica a ser desenvolvida em 1.600 (mil e seiscentas) horas referenciais, na qual os graduandos teráo acesso a conhecimentos específicos das opçóes em bacharelado ou licenciatura ${ }^{8}$.

Um outro aspecto trazido por esta norma é a intervenção profissional especializada, que deve ser dada à pessoa com deficiência tanto na etapa comum como na etapa específica, o que revela uma grande preocupação com os direitos das pessoas com deficiência e o papel que deve ser exercido pelos profissionais da área neste sentido.

Quanto aos conhecimentos preconizados na formação da primeira etapa - a comum -, são contempladas quatro dimensóes de saberes (Conhecimentos biológicos, psicológicos e socioculturais; Conhecimentos das dimensóes e implicaçóes biológicas, psicológicas e socioculturais da motricidade humana/movimento humano/ cultura do movimento corporal/atividade física; Conhecimento instrumental e tecnológico e Conhecimentos procedimentais e éticos da intervenção profissional em Educação Física) ${ }^{8}$.

No primeiro grupo de conhecimentos da etapa comum são trazidos saberes relacionados ao corpo humano e sua estrutura e funcionamento, de um lado, e aos aspectos mentais dos indivíduos, de outro, com o estudo dos campos psicológico, antropológico, 
histórico, social, cultural e outros, deixando-se em aberto a possibilidade de serem incluídos mais áreas de estudos relacionadas aos aspectos físicos e mentais dos indivíduos.

No segundo grupo de conhecimentos, colocam-se como conceitos importantes à área os relacionados às implicaçôes biológicas, psicológicas e socioculturais da motricidade, campo na qual devem ser exploradas a origem do movimento corporal e suas implicaçóes sociais a partir de cada cultura.

O terceiro grupo se encontram os conhecimentos instrumentais e tecnológicos, que são aqueles relacionados a aspectos técnicos da construção da pesquisa e da comunicação científica, bem como daqueles relacionados ao contato com indivíduos que não são da área.

Por fim, no último grupo de saberes, encontramse os procedimentais e éticos, com as disposiçóes sobre a forma de atuação na prática, o que envolve as regras jurídicas sobre a intervenção e trabalho dos futuros profissionais com o público, com ênfase aos riscos e benefícios das práticas de educação física, sua sustentabilidade, aspectos relacionados à cultura do contexto social e às diferenças individuais.

Deve-se enfatizar a formaçâo ética em todas as dimensôes, como pode ser interpretado do parágrafo único do artigo $6^{\circ}$.

Parágrafo único. A formação ética em Educação Física, de que trata o caput, deverá incluir, ainda, a prevenção do uso de meios ilícitos e danosos à saúde no cotidiano das práticas corporais, especialmente nas de caráter competitivo ou que visem ao desenvolvimento físico de crianças e adolescentes. ${ }^{8}$

A ética trazida neste ponto das diretrizes pode ser compreendida tanto como a área responsável por estudar os hábitos sociais, que vão além das manifestaçóes biológicas, como a área que se preocupa com a forma de agir que atinja o bem social, o coletivo?. Enfatiza-se, no texto das diretrizes, a necessidade de prevenir o uso de meios ilícitos e danosos à saúde nas práticas corporais, com uma preocupação com as atividades competitivas no desenvolvimento de crianças e adolescentes.

As quatro dimensōes revelam uma interface indireta com o conhecimento e aplicação dos direitos humanos na prática do profissional de Educação Física, uma vez que não foi trazido no texto da resolução, de forma expressa, como estes poderiam ser inseridos nos saberes enumerados no artigo $6^{\circ}$, de modo que os cursos ficam livres para pensar suas disciplinas a partir dos quatro campos indicados.

\section{Formaçáo específica em licenciatura em educaçáo física}

Após a etapa comum, com a escolha entre o término do curso com a formação específica em licenciatura ou bacharelado, o estudante segue seus estudos com um novo direcionamento para a apreensáo de conhecimentos que estáo na base de sua prática.

Com a escolha pelos estudos na licenciatura em Educação Física, a formação fica vinculada a um conjunto de requisitos, previstos no art. $9^{\circ}$, dos quais destacamos o reconhecimento da diversidade e complexidade da educação no contexto na qual está inserida (II); a busca pela melhoria e democratização do ensino, partindo-se da igualdade de condiçóes de acesso e permanência na escola (III); a necessidade de articular as diretrizes com as normas da Educação Básica organizadas pelo Conselho Nacional de Educaçáo e pelo Ministério da Educação (IV); ampliação do conceito de docência como ação educativa, o que pressupóe uma ação intencional e metódica que envolve conhecimentos específicos da área e os valores éticos, linguísticos, estéticos e políticos da sociedade (VII); a necessidade de formaçáo inicial e continuada dos professores de Educação Física, para que sejam capazes de contextualizar conhecimentos teóricos e práticos em sua atuação.

A formação do futuro licenciado em Educação Física deve ser perpassada pela educação em Direitos Humanos, estando ela prevista no artigo $10 \mathrm{da}$ respectiva resolução:

Art. $10 \mathrm{O}$ Licenciado em Educação Física terá formaçáo humanista, técnica, crítica, reflexiva e ética qualificadora da intervençáo profissional fundamentada no rigor científico, na reflexáo filosófica e na conduta ética no magistério, ou seja, na docência do componente curricular Educaçáo Física, tendo como referência a legislaçáo própria do Conselho Nacional de Educaçáo para a área. ${ }^{8}$ (Grifos nossos)

São buscadas no futuro professor capacidades que permitam que os saberes técnicos dialoguem com a realidade de forma crítica, tendo como ponto de partida o homem e a sociedade, uma vez que todo e qualquer magistério deve ser perpassado pela conduta ética que deve buscar a realizaçáo do máximo de bem comum a todos.

Continua-se com a preocupação, iniciada na etapa 
comum, com as práticas integradoras, que devem continuar com um percentual de $10 \%$ (dez por cento) nesta etapa (art. 13). Estimula-se a formação no âmbito das políticas públicas e da gestão da educação para o desenvolvimento de pessoas e organizaçóes, além da própria sociedade (art. 14).

Em relação às disciplinas que devem que precisam ser oferecidas nas instituições de ensino, o artigo 15 traz uma lista de conteúdos programáticos que devem se fazer presentes na formação dos futuros profissionais, entre os quais destaca-se a preocupação com a diversidade: "[...] k) Educação Física Escolar em ambientes não urbanos e em comunidades e agrupamentos étnicos distintos."

Para o curso de licenciatura são trazidas atividades de preparação para a docência em instituiçóes de educação; pesquisa e estudos da legislação educacional; e pesquisa e estudo das relaçóes de trabalho, de educação, diversidade, de direitos humanos, cidadania, dentre outras consideradas valores sociais da sociedade (art. 16).

\section{Entre o anunciado e o executado: o que refletem os currículos analisados?}

Nesta seção são analisados os currículos dos cursos de licenciatura presenciais em Educação Física, oficialmente expressos e postos em prática, atualmente, por cinco universidades federais brasileiras.

Conforme já detalhado no início deste trabalho, o corpus da pesquisa teve como objeto os currículos dos cursos de licenciatura em Educação Física, na modalidade presencial, ofertados pela Universidade Federal do Espírito Santo, como Estado representativo da região Sudeste, pela Universidade Federal do Rio Grande do Sul, como Estado representativo da regiáo Sul, pela Universidade Federal do Amazonas, como Estado representativo da região Norte, pela Universidade Federal de Pernambuco, como Estado representativo da região Nordeste e pela Universidade Federal de Mato Grosso, como Estado representativo da regiāo Centro-oeste.

Ainda a título de esclarecimento, fundamental relembrar que a primeira fase da análise se deu no intuito de contemplar a presença ou ausência específica da disciplina Direitos Humanos ou Educação em Direitos Humanos nos cinco currículos já mencionados.

Dessa forma, tem-se que, nos cinco projetos pedagógicos de cursos e matrizes curriculares estudadas, constatou-se a ausência da disciplina Direitos Humanos e/ou Educação em Direitos Humanos na sua totalidade, isto é, em 100\% do corpus de análise.
Para melhor compreensão do que fora encontrado, apresenta-se o QUADRO 2.

Após tal análise, buscou-se ampliar o olhar para cotejar a presença das disciplinas humanísticas e a proporção que estas representam, em contraponto às disciplinas chamadas de tecnicistas, nesses mesmos currículos.

No projeto político pedagógico e na matriz curricular da Universidade Federal do Espírito Santo, só foram constatadas duas disciplinas de caráter mais humanístico, a saber: Educação e Inclusão; Educação Física, Adaptação e Inclusão, cada uma com 60 horas aulas, ofertadas como obrigatórias. Todavia, ao fazer uma análise detalhada das aludidas ementas, observa-se um conteúdo voltado a discutir quase que tão somente elementos étnico-raciais, questóes ambientais e algumas outras diversidades de forma superficial, o que é bem diminuto em relação ao que se concebe, de fato, como necessário para uma preparação humanística.

Ao observar a carga horária total do curso acima referido, que equivale a $3.095 \mathrm{~h}$, percebe-se que a vertente humanística corresponde apenas a $3,87 \%$ da formação total ali propugnada, como mostra a FIGURA 2.

Analisando o projeto político pedagógico e a matriz curricular da Universidade Federal do Rio Grande do Sul, denota-se a presença das disciplinas Sociologia da Educação, Filosofia da Educação como obrigatórias, com carga horária de $30 \mathrm{~h}$ cada e, ainda, a presença de Antropologia do Corpo e da Saúde, também com carga horária de 30h, só que em caráter eletivo.

Fazendo a leitura exploratória das ementas, a fim de perceber o nível do que é abrangido em cada disciplina objeto de análise, é inconteste que a vinculação das mesmas é feita com questôes de corporeidade que envolve a própria natureza do curso, deixando de fora todo eixo teórico-conceitual que se espera para uma preparação mais cidadã do estudante.

Também se for feita comparação de carga horária, ainda que se contemple a disciplina eletiva já apresentada, tem-se um montante de $90 \mathrm{~h}$ de disciplinas humanísticas em um curso cujo universo abarca a carga horária total de $3.210 \mathrm{~h}$, fazendo com que essas humanísticas ocupem tão somente $2,8 \%$ da matriz curricular, de acordo com o que se visualiza na FIGURA 3.

Passando-se à análise do projeto políticopedagógico e da matriz curricular da Universidade Federal do Amazonas, constata-se a presença de uma única disciplina de cunho humanístico, a saber: Dimensôes Socioantropológicas da Educação Física e do Esporte. 
QUADRO 2 - Presença/ausência da disciplina direitos humanos e/ou educação em direitos humanos nos cursos analisados.

\begin{tabular}{|c|c|c|c|}
\hline Nome da Universidade & Região Brasileira & Disciplina Direitos Humanos & $\begin{array}{c}\text { Disciplina Educação em Direitos } \\
\text { Humanos }\end{array}$ \\
\hline Universidade Federal do Espírito Santo & Sudeste & Ausente & Ausente \\
\hline $\begin{array}{l}\text { Universidade Federal do Rio Grande } \\
\text { do Sul }\end{array}$ & Sul & Ausente & Ausente \\
\hline Universidade Federal do Amazonas & Norte & Ausente & Ausente \\
\hline Universidade Federal de Pernambuco & Nordeste & Ausente & Ausente \\
\hline Universidade Federal do Mato Grosso & Centro-oeste & Ausente & Ausente \\
\hline
\end{tabular}

FIGURA 2 - Proporção das disciplinas humanísticas em relação às disciplinas tecnicistas no curso de Licenciatura em Educação Física da UFES.

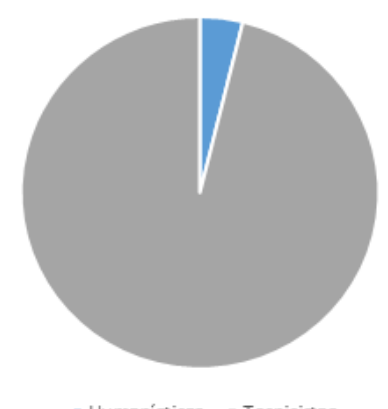

Fonte: Dados de pesquisa.

FIGURA 3 - Proporção das disciplinas humanísticas em relação às disciplinas tecnicistas no curso de Licenciatura em Educação Física da UFRGS.

Fonte: Dados de pesquisa.

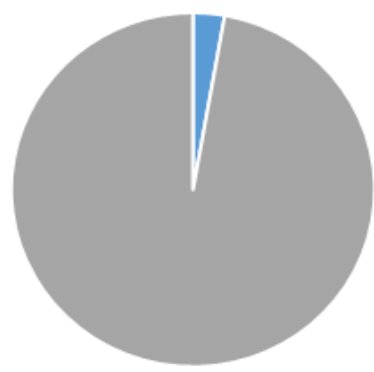

- Humanísticas $2,8 \% \quad$ " Tecnicistas 
Ressalta-se que a disciplina, ofertada como obrigatória e com carga horária de $60 \mathrm{~h}$, possui, de acordo com o que está posto na respectiva ementa, um viés que traz aspectos do homem e da sua vivência em sociedade atrelados à prática esportiva como raiz de sociabilidade e elo mais forte do humano na sua concepçáo natural. Tal abordagem, apesar de importante e bem interessante ao curso em questão, não contempla, todavia, os demais postulados da Educação em Direitos Humanos, ficando aquém do que se espera nesse aspecto específico.

No demonstrativo de comparação da carga horária, tem-se que em um currículo que totaliza $3.140 \mathrm{~h}$, a disciplina suscitada, com $60 \mathrm{~h}$, constitui um quantum de 1,9\%, conforme observado na FIGURA 4.

Chegando à região Nordeste, com o estudo do projeto político-pedagógico e currículo da Universidade Federal de Pernambuco, visualiza-se a presença de três disciplinas humanísticas, quais sejam: Educação Física e Filosofia, Bases Antropológicas aplicadas à Educação Física e Fundamentos da Sociologia, todas ofertadas em caráter obrigatório, tendo as duas primeiras cargas horárias de $45 \mathrm{~h}$ cada e a última $60 \mathrm{~h}$.

Nesse caso, também percebe o que se falou anteriormente acerca do curso de Educação Física da UFAM, a saber: há alguns conteúdos filosóficos, sociológicos e antropológicos, mas que buscam conectar esses saberes com foco na ideia de que o corpo tem um significado para além da estética, representando elemento da individualidade humana, que traz em si cargas antropológicas e emocionais que extrapolam a dimensão física.

Sem minimizar a relevância dessas abordagens, até porque a presente IES tem, de acordo com ementas de disciplinas, uma preocupação em esboçar uma visão mais universal do homem, não se pode deixar de demarcar que está de fora dessas ementas uma série de conteúdos voltados à formação do estudante com vistas à emancipação humana, calcada nos reais pilares dos Direitos Humanos.

Em dados mais numéricos, tem-se aqui que em um currículo que totaliza $2.970 \mathrm{~h}$, as disciplinas humanísticas representam 5\% desse currículo, como se pode vislumbrar na FIGURA 5.

Por fim, ao realizar estudo do projeto políticopedagógico e da matriz curricular da Universidade Federal do Mato Grosso, constatou-se a presença de quatro disciplinas humanísticas, sendo duas em caráter obrigatório e duas em caráter eletivo.

Como obrigatórias, encontram-se a Filosofia da Educaçáo e a Sociologia do Esporte, cada uma com carga horária de $64 \mathrm{~h}$. Como eletivas há a presença de "Estudos de Gênero e atividade Física" e "Tópicos em cultura e diversidade étnico-racial", também, com $64 \mathrm{~h}$ cada uma.

Aqui, não se pode deixar de considerar que, embora não haja disciplina específica de Direitos Humanos e/ ou Educação em Direitos Humanos, como não há em nenhum dos outros currículos estudados, tem-se que de vários conteúdos da temática são contemplados nas citadas disciplinas, mais especificamente nas eletivas já nominadas.

Ao fazer a representação gráfica dessa proporção de carga horária, em uma matriz que totaliza 3.224 horas e na qual 256 h são de disciplinas humanísticas (FIGURA 6), tem-se o percentual de $7,9 \%$ dedicado a tal componente curricular, nos exatos termos que seguem.

Assim, após a análise de cada projeto político pedagógico e de cada currículo estudado, em suas dimensóes mais específicas e que se aproximam do problema levantado na presente pesquisa, bem como diante da ausência da disciplina Direitos Humanos e/ou Educação em Direitos Humanos e do quantitativo de disciplinas tecnicistas encontradas em todos os currículos, pode-se inferir que a proporção dedicada à formação humanística é insuficiente ao perfil profissional que se defende neste trabalho.

Não se observa na formatação curricular que as disciplinas dialogam entre si no decorrer do curso. Ao contrário, percebe-se que há a carga inicial dedicada às já mencionadas disciplinas humanísticas, parecendo, em seguida, existir uma barreira para que os holofotes sejam voltados às chamadas "profissionalizantes", às que fecham o estudante no mundo das técnicas que farão parte da sua rotina de trabalho.

Assim, disciplinas como Anatomia, Biomecânica, Bioquímica Fisiologia, Cinesiologia, Controle Motor, Metodologia do Ensino do Handebol, do Ensino da Dança, do Ensino da Ginástica Olímpica, do Ensino da Natação, do Ensino do Futebol, do Ensino da Ginástica Rítmica e Desportiva, do Ensino do Futsal, do Ensino do Voleibol, do Ensino do Basquetebol, dentre outras, são alguns dos exemplos mais comuns de matérias que ocupam quase que a integralidade dos currículos dos referidos cursos.

Nessa perspectiva, apresenta-se na TABELA 3 uma tabela decrescente, com as 05 (cinco) universidades cujos currículos foram analisados, acompanhadas respectivamente das representaçóes, em termos percentuais, do que corresponde às disciplinas humanísticas em relação à carga horária total do curso. 
FIGURA 4 - Proporção das disciplinas humanísticas em relação às disciplinas tecnicistas no curso de Licenciatura em Educação Física da UFAM.

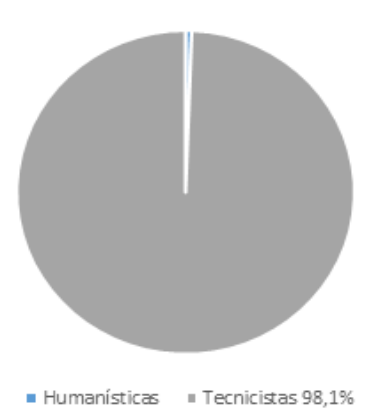

Fonte: Dados de pesquisa.

FIGURA 5 - Proporção das disciplinas humanísticas em relação às disciplinas tecnicistas no curso de Licenciatura em Educação Física da UFPE.

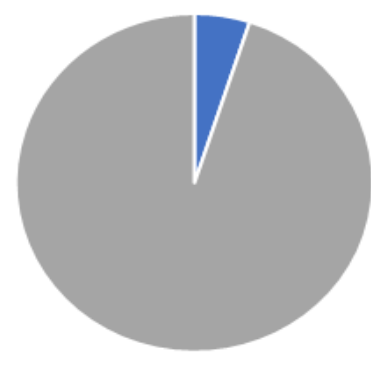

Fonte: Dados de pesquisa.

- Humanísticas " Tecnicistas

FIGURA 6 - Proporção das disciplinas humanísticas em relação às disciplinas tecnicistas no curso de Licenciatura em Educação Física da UFMT.

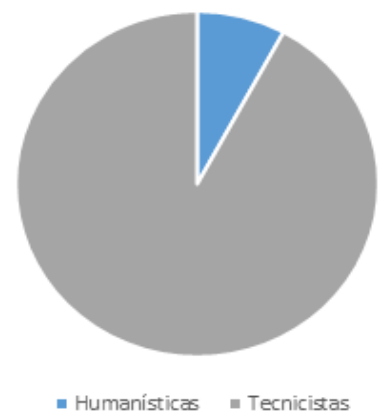

Fonte: Dados de pesquisa. 
TABELA 3 - Percentual da carga horária das disciplinas humanísticas em relação à carga horária total do curso.

Fonte: Dados de pesquisa.

\begin{tabular}{lc}
\hline IES & $\begin{array}{c}\text { Percentual da Carga Horária das Disciplinas } \\
\text { Humanísticas em Relaçáo à Carga Horária Total do Curso }\end{array}$ \\
\hline UFMT & $7,9 \%$ \\
UFPE & $5,0 \%$ \\
UFES & $3,87 \%$ \\
UFRGS & $2,80 \%$ \\
UFAM & $1,9 \%$ \\
\hline
\end{tabular}

Observa-se, dessa forma, que das 05 (cinco) universidades cujos currículos foram objeto de análise detalhada, pode-se detectar que apenas 02 (duas) apresentam número igual ou maior a $05 \%$ de sua carga total destinadas às disciplinas humanísticas, o que corrobora as curiosidades norteadoras das hipóteses e do problema geral deste estudo, mostrando, ainda, a necessidade urgente de se (re)pensar a formação universitária como um todo, seja nas licenciaturas, seja nas graduaçóes, a fim de se propagar uma educação libertária como preceituado pelos ideias pedagógicos e humanísticos mais hodiernos.

\section{Considerações finais}

Ao longo do que fora declinado, com análises das estruturas curriculares dos cursos de Licenciatura em Educação Física das Universidades Federais do Espírito Santo, Rio Grande do Sul, Amazonas, Pernambuco e Mato Grosso, constatou-se que os Direitos Humanos, assim como a formação humanística desses estudantes, não são tratados como anteposição de uma realidade essencial, mostrando que ainda são mantidos os ditames do tecnicismo.

Assim, a posição de um currículo que veja a perplexidade sua própria estrutura é uma atitude da educação que educa a si, em que a importância de se enxergar nessa relaçáo o cuidado com o ato de educar é imprescindível quando se pensa a sua dinamicidade. Afirma Arendt ${ }^{10}$ :

A tarefa educacional é intrinsecamente complexa, pois educar é simultaneamente proteger a criança das pressóes do mundo e proteger o mundo contra as pressóes e transformaçôes que advêm da capacidade humana para a ação e para o discurso em comum, própria dos recém-chegados. (p. 190) $)^{10}$

É evidente que os anacronismos presentes nesses cursos aqui trabalhados emanam da formação básica. Que essa "criança" citada pela autora como recémchegada é também o aluno recém-chegado às aludidas licenciaturas, e, para maior precisão, aos cursos de nível superior. Quando o currículo é pouco valorado na sua essência, os agentes e receptores tornam-se o objeto dessa subalternização. Eis, portanto, o desafio da Educação em Direitos Humanos na discussão curricular, não como um problema inclusivo da Educação ou uma reflexão da Pedagogia, mas um problema da universalidade humana.

O primado da Pedagogia é um legado de uma cultura que perpassa o "mundo da vida" desde o primeiro ato antropológico da história. Pensar na formação desse "recém-chegado" como formador da humanidade não é uma atitude restrita a uma área específica do conhecimento, ou vaidade teórica, tampouco uma atitude de transformação, é entender que qualquer decisão tomada no âmbito da educação, seja nos processos de ensino e aprendizagem, seja na gestão educacional, é uma atitude por toda humanidade. Toda decisão humana, mesmo particular, é uma repercussão na humanidade.

Da mesma forma, qualquer decisão sobre a 
configuração curricular não é um ato isolado, mas um ato que reflete em toda uma sociedade. Eis, portanto, o que conclama este trabalho: a necessidade de um currículo perpassado pelos Direitos Humanos como o modelo de configuração socioeducacional capaz de buscar garantir o equilíbrio entre o humanismo, a ciência, a técnica, as artes e, sobretudo, capaz de romper com a desumanização tão gritante na segunda década desse século.

\begin{abstract}
The (in)visibility of Human Rights in Physical Education bachelor courses at Brazilian federal universities.

This article investigated the Physical Education teachers' preparation aiming to understand whether the Human Rights Education's components are included in this preparation and, if present, how satisfactorily is in the sense of not only training people capable only of technical knowledge and skills, but we also seek to forgethem completely, making them subjects of rights in the broadest sense of the word. From a qualitative approach in based on the Content Analysis, it discussesfundamental concepts ofEducation in Human Rights and the recommendations from the National Curriculum Guidelines which regulates Physical Education undergrad coursed to undertake the analysis of political pedagogical projects and the curriculum of such undergraduate courses offered at Brazilian federal universities. The results revealed the subordination of the humanistic elements compared to technical contents. The conclusion of the study reinforces the need for more research on this topic and the conviction that, somehow, the reflection presented can contribute to deep discussion that may feedback the humanism in university ambivalence.
\end{abstract}

KEYWORDS: Human rights education; Federal universities; Physical education.

\title{
Referências
}

1. Bardin L. Análise de conteúdo. São Paulo: Edições 70, 2016.

2. Brasil. Sistema e-Mec. Disponível em: https://emec.mec.gov.br. Acesso em 02 ago 2021.

3. Brasil. Comitê Nacional de Educação em Direitos Humanos. Plano Nacional de Educaçáo em Direitos Humanos. Secretária Especial dos Direitos Humanos. Presidência da República. Ministério da Educação. Ministério da Justiça. Unesco, 2007.

4. Brasil. Plano Nacional de Educação, Lei no 13.005/2014.

5. Assembleia Geral da ONU. (1948). "Declaração Universal dos Direitos Humanos" (217 [III] A). Paris. Disponível em https://brasil.un.org/pt-br/91601-declaracao-universal-dos-direitos-humanos.

6. Brasil. Lei de Diretrizes e Bases da Educação Nacional. Lei no 9.394. 1996. Disponível em: http://portal.mec.gov.br/ seed/arquivos/pdf/tvescola/leis/lein 9394.pdf.

7. Santos BS. A crítica da razáo indolente: contra o desperdício da experiência. In: Para um novo senso comum: a ciência, o direito e a política na transição paradigmática. 4. ed. São Paulo: Cortez, 2002.

8. Brasil. Diretrizes Curriculares Nacionais do curso Educação Física estấo previstas na Resolução no 6 de 18 de dezembro de 2018.

9. González JF; Fensterseifer, PE. Dicionário crítico de educação física. Ijuí/RS: Unijuí, 2014.

10. Arendt H. A vida do espírito: o pensar, o querer, o julgar. Rio de Janeiro: Relume Dumará, 1995. 
Palmeira LLL et al.

\begin{tabular}{r|r} 
ENDEREÇo & \\
Lana Lisiêr de Lima Palmeira & \\
Universidade Federal de Alagoas & \\
Programa de Pós-graduação em Educação & Submetido: 01/12/2021 \\
Campus A. C. Simões & Aceito: 06/12/2021 \\
BR 104 Norte, Km 96,7 & \\
57072-970 - Maceió - AL - Brasil & \\
E-mail: lana.palmeira@arapiraca.ufal.br &
\end{tabular}

